Jpn. J. Human Genet. 30, 51-56, 1985

\title{
PFEIFFER SYNDROME OR SAETHRE-CHOTZEN
}

\section{SYNDROME?}

\author{
Masato Tsukahara, Keiji Hagiwara, and Tadashi KajII \\ Department of Pediatrics, Yamaguchi University School of Medicine, \\ Ube, Yamaguchi 755, Japan
}

\begin{abstract}
Summary A 4.5-year-old girl with clinical features of both the Pfeiffer and Saethre-Chotzen syndromes is described. She was severely mentally retarded, had brachycephaly, craniosynostosis, prominent forehead, proptosis, midface hypoplasia, low-set and small ears, a high arched palate, broad thumbs and great toes, short phalanges of the third toes, and soft tissue syndactyly between the second and third fingers and between the second and third toes. In addition, she showed several clinical features characteristic of the Saethre-Chotzen syndrome, including a low-set frontal hairline, mild ptosis, a deviated nasal septum, and a cleft soft palate. Thus, the disease in the patient may represent a transitional form between the Pfeiffer and Saethre-Chotzen syndromes. Her father and paternal grandmother each had a few clinical features of the disease, indicating that the disease was inherited in an autosomal dominant fashion.
\end{abstract}

\section{INTRODUCTION}

The acrocephalosyndactyly syndromes are classified into six types: Apert syndrome (type I), Apert-Crouzon disease (type II), Saethre-Chotzen syndrome (type III), Waardenburg syndrome (type IV), Pfeiffer syndrome (type V), and acrocephalopolysyndactyly or Noack syndrome (McKusick, 1983). Waardenburg syndrome is now considered identical to Saethre-Chotzen syndrome. These syndromes are inherited as autosomal dominant traits with variable expressivity. Pfeiffer syndrome is characterized by craniosynostosis, broad thumbs and great toes, and partial soft tissue syndactyly of the hands and feet. The Saethre-Chotzen syndrome is characterized by craniosynostosis, a low-set frontal hairline, facial asymmetry, ptosis of the eyelids, a deviated nasal septum, and some degree of brachydactyly and cutaneous syndactyly, particularly between the second and third fingers.

We describe here a Japanese girl with clinical features of both the Pfeiffer and Saethre-Chotzen syndromes.

Received January 23, 1985 ; revised version received March 20, 1985 


\section{CASE REPORT}

The patient is a 4.5-year-old girl. She was born after a 36 -week pregnancy to a 28-year-old, gravida II, para I, mother and a 28 -year-old father, both healthy and unrelated. Neither a history of viral infection nor X-ray exposure during the pregnancy existed. There was a 7-year-old elder sister who appeared normal.

The patient at birth weighed $1,850 \mathrm{~g}(-3.1 \mathrm{SD})$ and measured $44.3 \mathrm{~cm}(-2.6$ SD). Abnormalities noted soon after birth included: a flat facies, a depressed nasal tip, low-set ears and a cleft palate. She was discharged at age 2.5 months. Her anterior fontanelle sutured naturally at age 10 months. During early infancy she suffered from recurrent respiratory and mid-ear infections. Her cleft soft palate was surgically repaired at age 2.5 years.

When seen at age 3 years, she weighed $9.6 \mathrm{~kg}(-2.7 \mathrm{SD})$, her height was 87 $\mathrm{cm}(-1.8 \mathrm{SD})$ and her head circumference was $45 \mathrm{~cm}(-2.2 \mathrm{SD})$. Abnormal craniofacial features noted at that time included brachycephaly, craniosynostosis of the coronal and sagittal sutures, a prominent forehead, synophrys, proptosis, bilateral mild ptosis, antimongoloid slanting of the palpebral fissures, midface hypo-

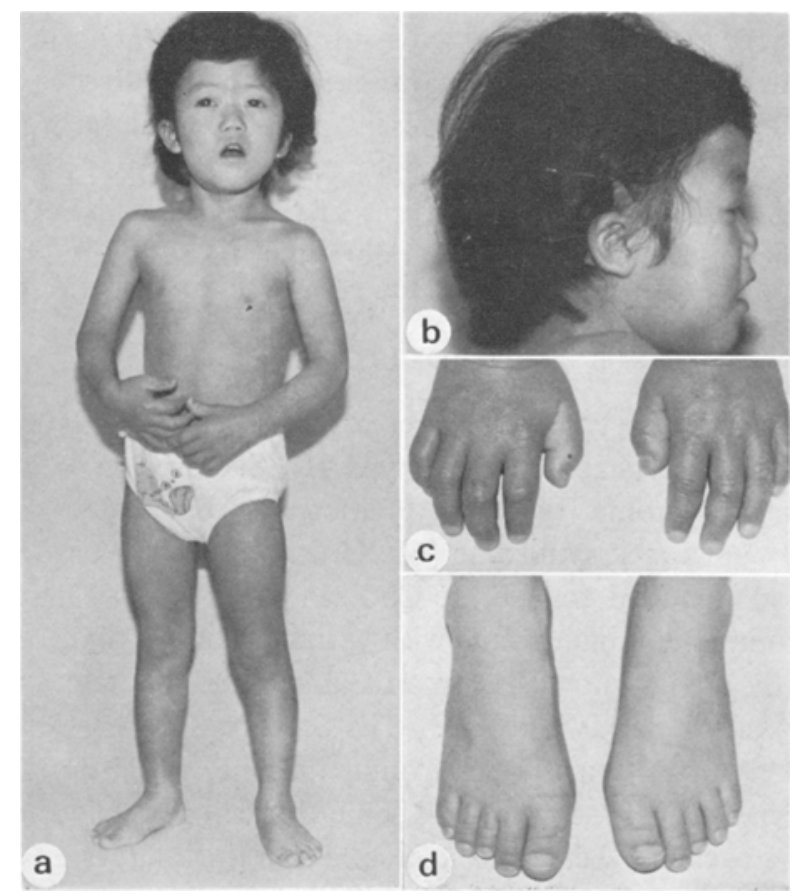

Fig. 1. The patient at age 3 years. $a$ and $b$, note low anterior hairline, prominent forehead, proptosis, ocular hypertelorism, midface hypoplasia, small low-set ears and relative prognathism. c, broad thumbs. $d$, broad great toes and short third toes. 
plasia, small low-set ears (ear length; rt $42 \mathrm{~mm}$; It $38 \mathrm{~mm}$ ), a depressed nasal bridge, a short nasal septum, a small mouth, relative prognathism, a high arched palate and dental malocclusion (Fig. 1a, b). She also had broad thumbs (Fig. 1c), clinodactyly of the fifth fingers, soft tissue syndactyly between the second and third fingers of both hands, broad great toes (Fig. 1d), short third toes, and soft tissue syndactyly between the second and third toes of both feet. Funduscopic examination revealed no abnormal findings. Intraocular pressure at that time was $20.6 \mathrm{~mm}$ $\mathrm{Hg}$ bilaterally. G-banding chromosome analysis revealed a 46,XX karyotype. Her developmental milestones were delayed. She sat alone at 12 months, crawled at 19 months, and walked alone at 29 months. Her developmental quotient at age 3 years was estimated at 40 using the Tsumori and Inage Scale of Developmental Maturity (1977). When last seen at age 4.5 years, she spoke a few words, but no meaningful sentence. She was not toilet-trained.

$X$-ray examination (Fig. 2). Roentgenograms of the skull at age 3 years revealed fusion of the coronal sutures, partial fusion of the sagittal suture, prominent

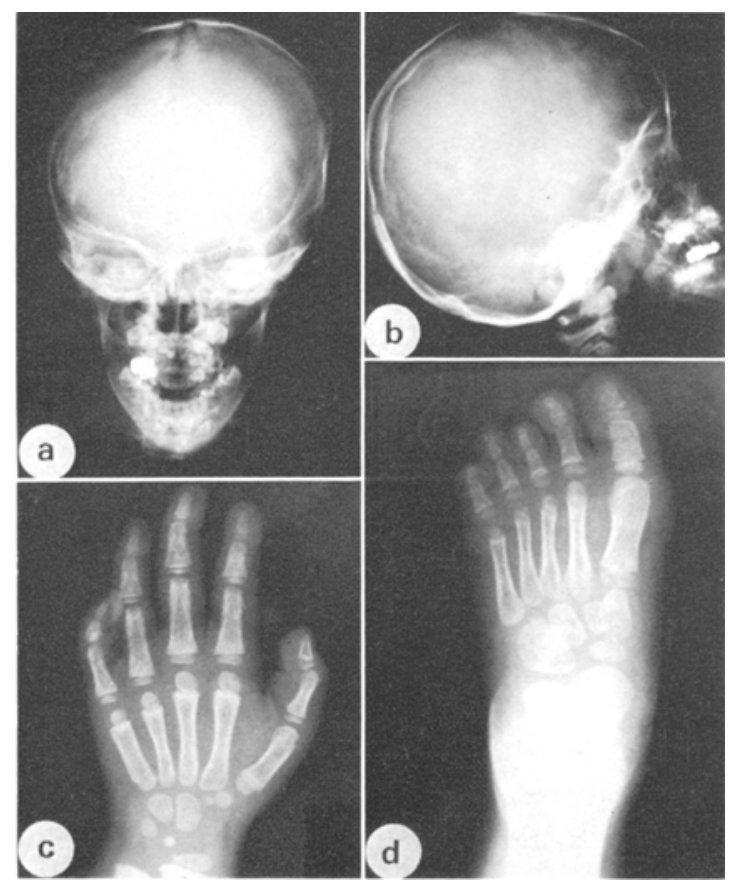

Fig. 2. Roentgenograms. $a$ and $b$, the skull with a shallow anterior cranial fossa, a small posterior fossa, increased digital markings, maxillary hypoplasia, a deviated nasal septum and a narrow palate. c, left hand with soft tissue hypertrophy of the thumb and short middle phalanx of the fifth finger. $d$, left foot with broad metatarsal and phalanges of the great toe, short proximal and middle phalanges of the third toe. 
frontal bones, a shallow anterior cranial fossa, a small posterior fossa, increased digital markings, maxillary hypoplasia, a deviated nasal septum, and a narrow palate. The hands showed soft tissue hypertrophy of the thumbs, short middle phalanges of the fifth fingers, and soft tissue syndactyly between the second and third fingers. The maturity of the carpal bones was at the 4-year-level. The feet showed broad metatarsals and phalanges of the great toes, short proximal and middle phalanges of the third toes, and soft tissue syndactyly between the second and third toes. A CT scan of the brain revealed no abnormalities.

Dermatoglyphics. Left fingers: Whorl (W), W, W, W, W; right fingers: W, Ulnar loop (LU), LU, W, W. The total finger ridge count was 163. The axial triradii were in the $\mathrm{t}^{\prime \prime}$ positions.

Family study (Fig. 3). There was no other family member with mental retardation. The paternal grandfather $(\mathrm{I}-1)$ was exposed to the atomic blast in Hiroshima at a distance of $2 \mathrm{~km} 7$ years before her father's birth.

The patient's father (II-1) had midface hypoplasia (Fig. 4) and broad great toes. A roentgenogram of his skull showed a shallow anterior fossa and midface hypoplasia. Furthermore, roentgenograms of his feet showed broad metatarsals and phalanges of the great toes.

Her paternal grandmother (I-7) showed midface hypoplasia, low-set ears, soft tissue syndactyly between the second and third fingers, and broad great toes (Fig. 5).
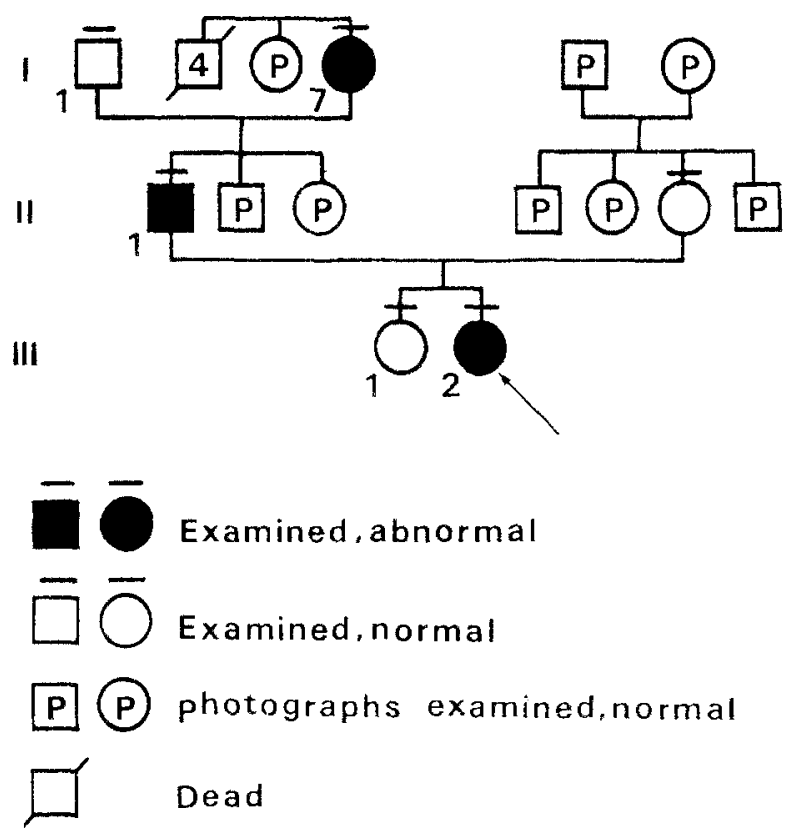

Fig. 3. Family tree. 


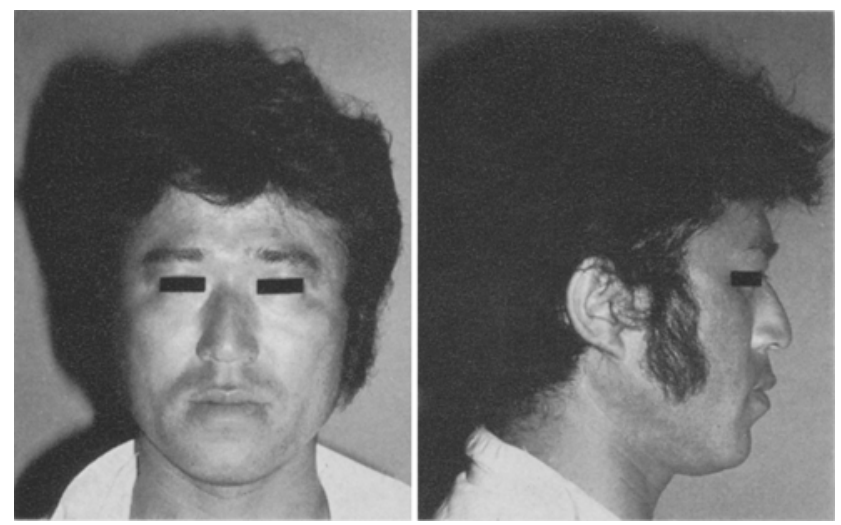

Fig. 4. The father. note his midface hypoplasia.

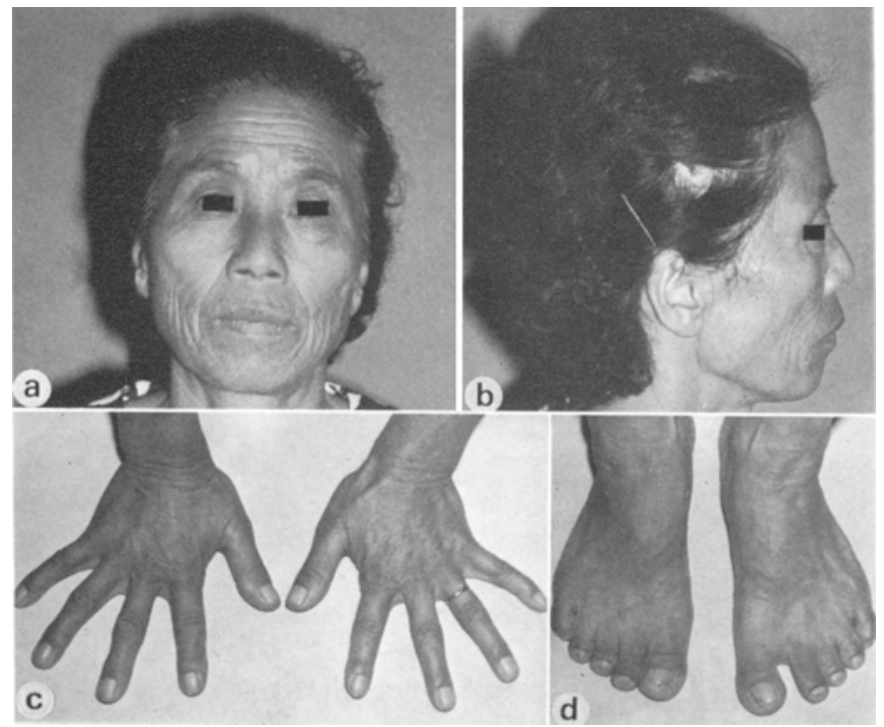

Fig. 5. The paternal grandmother. a and b, note midface hypoplasia and low-set ears. c, soft tissue syndactyly between the second and third fingers. d, broad great toes.

\section{DISCUSSION}

The patient we have described here is a girl with several clinical features characteristic of the Pfeiffer syndrome. These features include brachycephaly, craniosynostosis, a prominent forehead, ocular hypertelorism, proptosis, antimongoloid slanting of the palpebral fissures, midface hypoplasia, small low-set ears, a depressed nasal bridge, relative prognathism, a high arched palate, and dental malocclusion. 
Also noted were broad thumbs and great toes, clinodactyly of the fifth fingers, and soft tissue syndactyly between the fingers and between the toes. With the exception of proptosis and broad thumbs and great toes, these features are also characteristic of Saethre-Chotzen syndrome. With several features characteristic of the SaethreChotzen syndrome, specifically a low-set frontal hairline, ptosis of the eyelids, deviation of the nasal septum, and a cleft soft palate (Cohen, 1975), the patient appears to have been a transitional form between the Pfeiffer and Saethre-Chotzen syndromes. She was severely mentally retarded, which is an unusual finding in either syndrome. The presence or absence of mental retardation, however, cannot be used as a criterion for the classification of acrocephalosyndactyly syndromes, as it is a highly variable finding (Cohen, 1975).

The distinction between Pfeiffer and the Saethre-Chotzen syndromes is itself obscure. Robinow and Sorauf (1975) presented a family with members exhibiting either Pfeiffer or Saethre-Chotzen syndromes. Other relatives displayed phenotypic combinations of these two disorders. Jackson et al. (1976) reported an Amish kindred in which the phenotypic expression was so variable that all dominant acrocephalosyndactyly types, except for the Apert type, were noted.

In view of these observations, it is difficult to decide whether the disease in the patient we described is a new disease or whether it indicates the possibility that Pfeiffer and Saethre-Chotzen syndromes are actually variable expressions of a single gene. Based on our observations, we tend to favor the latter interpretation.

\section{REFERENCES}

Cohen, M.M. 1975. An etiologic and nosologic overview of craniosynostosis syndrome. Birth Defects Orig. Art. Ser. XI (2): 136-189.

Jackson, C.E., Weiss, L., Raynolds, W.A., Forman, T.F., and Peterson, J.A. 1976. Craniosynostosis, midfacial hypoplasia, and foot abnormalities: An autosomal dominant phenotype in a large Amish kindred. J. Pediatr. 88: 963-968.

McKusick, V.A. 1983. Mendelian Inheritance in Man. Catalogs of Autosomal Dominant, Autosomal Recessive and $X$-Linked Phenotypes, 6th Ed., The Johns Hopkins Univ. Press, Baltimore, pp. 8-10.

Robinow, M. and Sorauf, R. 1975. Acrocephalopolysyndactyly type Noack in a large kindred. Birth Defects Orig. Art. Ser XI (5): 99-106.

Tsumori, M. and Inage, N. 1977. Developmental Screening Test for Infants. Dainippon-Tosho Co., Tokyo (In Japanese). 